\title{
About "Do Evaluation of Teaching” of Quaternity of The Training Mode of Exploration and Research
}

\author{
Wei Fu ${ }^{1}$ Pengguang Tang ${ }^{2}$ Qian Li Hao Xie Jian Fang \\ Chongqing Internet of Things Engineering Technology Research Center \\ Key Lab of Network Control Tech.\&Ins., Chongqing University of P\&T, Chongqing, 400065, China \\ E-mail: 61677822@qq.com
}

\begin{abstract}
With the development of modern society, all walks of life increasingly need innovative applied talents with strong hands-on skills. Aimed at the disadvantages of the traditional practice teaching mode, and through the analysis of training mode at home and abroad, this paper puts forward a "teaching evaluation" new training mode of quaternity.
\end{abstract}

Keyword: applied talents; practical teaching; quaternity

\section{INTRODUCTION}

Throughout higher education present situation, the current practical teaching in colleges and universities and applied talents training is still a disconnect between phenomenon, and the practice teaching is a bridge theory teaching to cultivate applied talents. So how to improve the traditional practice teaching mode, strengthen the practical teaching innovation, cultivate conforms to the market demand of the applied talents is the problem of higher education is imminent.

To reform and innovation for training mode in our country, promoting the "student-oriented" development of practice teaching that foreign successful practice patterns for training mode has a lot of experience that is worth studying and using for reference.

Such as the German "dual system", collaborative training model;"Cooperative education" in the United States, alternating training mode;"Teaching factory" in Singapore, analog simulation training mode; Australia's "apprenticeship", the scene teaching training mode and so on. Overseas training mode, are more pay attention to the idea of "student-oriented", highlight the transformation of roles between teachers and students and students learning style changes, weaken the traditional classroom form, increase the intensity of the scene teaching, and to arrange the training time, and in the process of practice with theory knowledge teaching, especially to guide and encourage students in the process of the field, and use a variety of learning opportunities and ways to carry out the development type, and then practice training makes the organic combination of theory teaching and practice teaching.[1]

In recent years, training mode in China also in the event of a huge change. Process Reengineering training mode, post actual operation type training mode, model driven training mode, professional simulation training pattern are in practice in the development of colleges and universities. The model at the heart of all is regarding students as main body, and building a specific simulation, simulation or real work environment conditions, complete the entire training process. Contemporary famous Professor Dayuan Jiang has brought forward "hand by hand, let go of the hand, cultivate nailer, use of hands and brain " and "learn to study while doing ,learn to do while studying, learn how to do , combine doing and studying" in the book named Work process-oriented curriculum development and curriculum system constructing. On the basis of "teaching learning" to increase effective evaluation system(the evaluation can include the teacher to student's evaluation, and can also include students to students' evaluation and students to the teacher's evaluation), and build a "teaching and learning evaluation " teaching mode and promote the 
harmonious advance of teaching and learning, really let the students do in the" learning by doing, learning enlightenment, realization of wake up, wake up in the bank of China "enlightenment, better realize the training goal. Therefore, good formation of training mode to cultivate students' independent ability to analyze and solve practical problems is critical.

\section{THE PROBLEM ABOUT PRACTICAL TEACHING IN YOUR COUNTRY'S COLLEGES AND UNIVERSITIES AT PRESENT}

\subsection{Traditional practical teaching emphasize the teacher, separate the class teaching and students' practice}

A complete class is divided into two phases. The former phase is the teacher teach the student some related knowledge about the course and case design idea in multi-media classroom, the student only need listen to the teacher and no need to operate. The latter phase is the teacher arrange experimental duties according to the former phase, and the student take practice in the laboratory. The two phases aren't at the same place or the same time, the student can't understand the learning content in time and apply it into project creation. Because of the long time, the teacher must make an example in the practical training, and the student only can copy the experimental duties. It's not good to develop the ability of creative thinking, even make the student increase the practical skill slow and the efficiency of practical teaching drop. ${ }^{[2]}$

\subsection{The student act as passive role in traditional practical teaching link}

The selfish departmentalism teaching model which is leaded by teacher is awlays chosed in traditional practical teaching link. Class teaching and practical training is obey to the teacher, the student only take on the role of passive learning. Such duck-stuffing teaching only pay attention to that the student learn by following the teacher's thought, it can't develop the student's conscious activity. The student can't thinking problem independently, develop creative thinking or the knowledge can't be comprehended by analogy. It must trap the increation of the student's skill, so the student can't be qualified the social post quickly.

\section{ABOUT THE TEACHING EVALUATION OF "FOUR ONE OF THE TRAINING MODE OF EXPLORATION AND RESEARCH"}

This paper proposed a "teaching evaluation" four one of the training mode, is in the process of training as the core, is evaluated with gripper, dominated by teachers, students as the main body, with projects as the carrier, by means of practice, and through the effective evaluation mechanism, to cultivate students' innovative and practice ability of an interactive teaching model.

"Teaching evaluation" four one of the new training pattern which teacher will work scientific research project or enterprise real case in the form of a task assigned to the student, the student to carry on the project training, teamwork, timely on group design project of self-evaluation, mutual and teacher comments on a combination of periodic evaluation, found the problem, teachers collect problem and its explanation, the student on the basis of innovative thinking, to modify the project, complete the training. "Teaching to do a review of the" four one of the new training pattern is shown in figure $1 .^{[3]}$

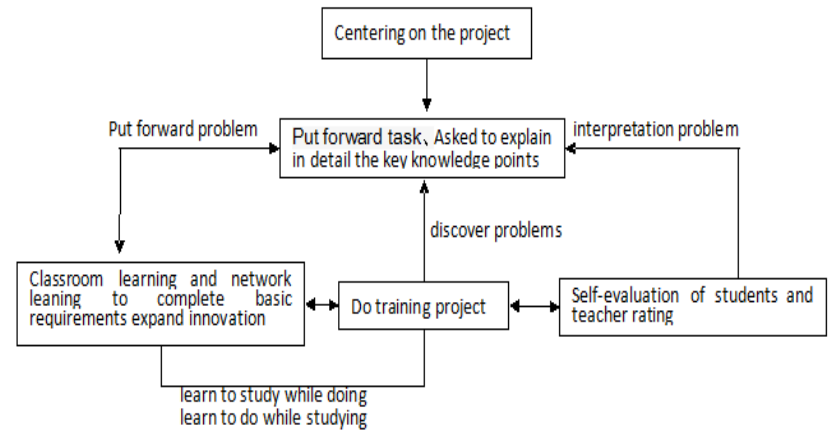

Figure 1 teaching evaluation of four

New training mode New training mode, follow the social personnel skills training standard, relying on the actual job requirements provide real case, teach, learn, do, review four link, layer upon layer clasped and interaction, form an organic whole. Here in Chongqing university of posts and telecommunications institute of automation control categories of undergraduate engineering training, for example, "teaching evaluation" four links.

\subsection{Teaching}

According to students practical situation and characteristics of a project as the guidance, according to the scientific research project, or the working process of 
the enterprise real case, teachers take the "total - points total" approach, let students view of the whole project, clear learning objectives, to design task decomposition, determine the teaching unit, and then merged into small project complete projects, and comb project of involved knowledge points. The whole process is like teach not, in the discussion of teaching in the teachers and students. Ask for each group stage reviews.

\subsection{Learning}

Students training for all advanced manufacturing engineering training center of Chongqing university of posts and telecommunications, lesson plans, teaching courseware, example teaching videos, homework, difficult point solutions, resources, etc., are uploaded on the center website, all the teachers and students are eligible to access broadband Internet access. Students in the process of listening to lectures if in doubt, in addition to turn to the teacher, also can take advantage of the convenient network learning resources, learning, and complete training, greatly promoting the improvement of the students' skill. ${ }^{[4]}$

\subsection{Doing}

During the practice training, we simulated The real working environment. The machine room of the advanced manufacturing engineering training center as the the projectresearch and development stuodio, the PCB plate making workshop, the SMTpatching workshop, the welding and assembling workshop Laboratory as the material object acture room . and the elecetromagnetic compatibility Laboratory product testing workshop, the industrial flow as the production experimental unit Teachers are valure as project chief consultant, building a professional situation. Introduction of Scientific Research Project and Introduction project resources. According to the principle of project driven organization of classroom teaching, let students group into several research and development team ( such as Hardware development group、Software research and development group、 Product production team、Product test group and so on ), Team member all on his duty, complete the project module independently. Students as identity of "virtual research personnel" to participate in the project development, To training in the offect of learning from doing and doing with learning "teching learning doing cross".

\subsection{Evaluating}

Group members raise questions via evaluating the project their own designed himself and by others, evaluate the skills. Creativity, applicability of project objectively, present the project starting point for improvement. And in this link, student can analyse the project Multi-dimension. Therefore, their thoughts were more wridely. And which is good for Strengthening the consciousness of innovation and Improve the ability of project development.

\section{CONCLUSION}

Training courses "teching learning doing" must pay attention to the flexibility and dynamic, This can carry on the reasonable adjustment according to the requirements of the course and students' actual situation, otheraise, the Integrated teaching mode is not only a cooperation between the teachers and students but also to the school management responsibilities , The school shall set specific training equipment and venues according to the course characteristics, so the Competent leadership and coordination level is a direct impact on that whether the teaching model can effectively implemented smoothly.

Through the observation of the whole teaching process and the analysis of the questionnaire survey results to the student Found that in the training class, the use of four integrated teaching mode can enrich classroom form, can strengthen the teaching effect, promote the feelings between teachers and students, greatly increase the students' practice ability and innovation ability. It is a total effective teaching mode.

\section{ACKNOWLEDGMENT}

Popular science series of Internet of things (cstc2012gg-kplB40006), Scientific and technological research project (popular science class) of Chongqing.

Science and technology research projects in 2012 of Chongqing board of education- - The research and application of wireless sensor network based on IPV6 in smart home(KJ120534).

Internet of things the interactive experience on the research and development of library science exhibits 
and teaching aids (cstc2012gg-kplB40005), scientific and technological research project (popular science class) of Chongqing.

IT popular science bases of Chongqing, key science base construction project of Chongqing.

Construction of automation graduate innovation education bases, key project of graduate education innovation of Chongqing University of P\&T.

Research and practice of the engineering training center construction (1201019), Chongqing higher education teaching reform research project.

\section{REFERENCES}

[1] Tong Shi-hua. Exploration of the high quality skill type talent training in the higher vocational colleges[J].Chongqing ; journal of Chongqing College of Electronic Engineering 2009.07(07),79-81

[2] Dan Fengru, Zhao Sumin, The research and reference of foreign training organization[J]. Liaoning Journal of Higher Vocational Education 2009(12)

[3] Xu Haoqin, Lu Chaohua, Computer science "teaching evaluation" exploration and practice of integrated teaching mode[J].Journal of Shayang Teachers College 2011(06)

[4] Zong Hairong, By four in one teaching method in the teaching of case study[J].Modern Reading 2012(10) 